X

1 роническое воспаление, инсулинорезистентность, псориаз - что общего? М.С. Расин

ВГУЗ «Украинская медицинская стоматологическая академия» 36011, г. Полтава, ул. Шевченко, д. 23

Псориаз признан системным иммуновоспалительным заболеванием. Установлено, что псориаз развивается под влиянием хронического системного воспаления и индуцируемой системным воспалением инсулинорезистентности на определенной генетической основе, т. е. является одной из клинических форм иммунометаболической болезни наряду с атеросклерозом, гипертонической болезнью, сахарным диабетом 2-го типа, ожирением и многими другими заболеваниями, тесная связь которых с псориазом установлена. Знание этиологии, патогенеза и молекулярных механизмов связи с другими клиническими фрормами иммунометаболической патологии открывает новые пути профилактики и лечения псориаза. Учитывая, что другие ассоциированные с псориазом заболевания, протекающие скрыто, часто имеют большее прогностическое значение для жизни и здоровья больного, чем легкие или среднетяжелые формы псориаза, необходимо не ограничиваться только констатацией диагноза и симптоматическим лечением, а активно участвовать в профилактике. Дебатируется вопрос о применении средств, подавляющих системное воспаление и инсулинорезистентность, в терапии псориаза.

Ключевые слова: псориаз, системное воспаление низкой интенсивности, инсулинорезистентность, атеросклероз, гипертония, сахарный диабет 2-го типа.

Контактная информация: profrasin@gmail.com. Вестник дерматологии и венерологии 2016; (5): 20—24.

\title{
Chronic inflammation, insulin resistance, psoriasis - which have in common?
}

\section{M.S. Rasin}

Ukrainian medical stomatological Academy

Shevchenko str., 23, Poltava, 36011, Ukraine

Psoriasis is recognized as system immune inflammatory disease at a certain genetic basis. It was found that psoriasis develops under the influence of chronic systemic inflammation low intensity (low grade inflammation) that induced insulin resistance, and is one of the clinical forms of the Immune Metabolic Disease (IMD), along with atherosclerosis, hypertension, type 2 diabetes, obesity and many other diseases, whose tight relationship with psoriasis are installed. Knowledge of the etiology, pathogenesis and molecular mechanisms of communication with other clinical forms of the IMD opens up new ways of prevention and treatment of psoriasis. Please note that other diseases associated with psoriasis, occurring hidden, often have greater predictive value for the life and health of the patient than mild or moderate forms of psoriasis, and be not limited to ascertaining the diagnosis and symptomatic treatment and actively participate in prevention. Debated question of the application of funds, suppressing systemic inflammation and insulin resistance in the treatment of psoriasis.

Key words: psoriasis, low grade inflammation, insulin resistens, atherosclerosis, hypertension, diabetes mellitus type 2.

Corresponding author: profrasin@gmail.com. Vestnik Dermatologii i Venerologii 2016; 5: 20—24. 
Псориаз признан хроническим системным медиируемым активированными дендритными клетками кожи воспалительным заболеванием с накоплением в очагах воспаления интерлейкина-23 и активированных Th-1 лимфоцитов (Th-17, Th-22) [1]. За последние годы накоплено большое количество данных, выявивших связь псориаза с другими воспалительными заболеваниями, к которым, в частности, относятся ожирение, сахарный диабет, атеросклероз, артериальная гипертония, неалкогольная жировая болезнь печени, синдром склерозированных яичников, доброкачественная гиперплазия предстательной железы, эректильная дисфункция и многие другие [2-6]. Все указанные (и не указанные) болезни связаны с системным вялотекущим воспалением (СВ) и индуцируемой им инсулинорезистентностью (ИР) [7]. Попытки объяснить системное воспаление следствием первичного воспаления кожи при псориазе или его сочетанием с ожирением несостоятельны, хотя бы потому, что явления СВ и ИР наблюдаются у больных и их кровных родственников до развития кожных симптомов и провоцируются теми же внешними фракторами, а также имеют общую генетическую основу с другими перечисленными выше процессами [8]. Для целей рациональной профилактики и поиска новых методов терапии псориаза важно иметь четкое представление об этиологических фракторах СВ, его связи с ИР и механизмах их участия в патогенезе псориаза. Этим вопросам посвящен настоящий обзор литературы.

Системное воспаление (системное вялотекущее воспаление, системное воспаление низкой интенсивности, low grade inflammation)

Системное вялотекущее воспаление - реакция иммунной системы на персистирующие повреждающие стимулы. В этиологии СВ основное место занимают: 1) хронический стресс, в том числе психосоциальный [9]; 2) избыточное по калорийности и содержанию липидов питание, ведущее к ожирению; 3) гипокинезия; 4) хронические бактериальные и вирусные инфекции, в том числе изменения в кишечной микрофлоре.

В развитии СВ большую роль играют генетические особенности как иммунной системы, так и физиологических систем, реагирующих на внешние стимулы.

При СВ активируются сигнальные пути ядерных транскрипционных фракторов (ЯТФ): каппа В (NFкB), AT-1 (активирующий протеин-1), МАР-киназного и др. в клетках крови и тканях, в макрофагах и их аналогах, лимфоцитах, адипоцитах. Выделяются цитокины: интерлейкины-1 и -6 (ИЛ-1, ИЛ-6), фрактор некроза опухолиальфа (ФНО- $\alpha$ ), что ведет к продукции острофазных протеинов: фибриногена, сиаловых кислот, С-реактивного белка (СРБ). Персистирование повреждающих фракторов обусловливает постоянно повышенный уровень цитокинов. СВ определяется как повышение уровня провоспалительных и антивоспалительных цитокинов в 2-4 раза, в отличие от острого локального воспалительного процесса, при котором наблюдается повышение уровня цитокинов в десятки и сотни раз [11]. Острое воспаление либо заканчивается нормализацией показателей, либо остается в фрорме СВ. СВ в эндотелии сосудов, мышечной и жировой тканях имеет особое значение [12]. Молекулярные механизмы, связывающие этиологические фракторы с активацией внутриклеточных сигнальных путей воспаления, изучены и представлены в ряде обзоров и экспериментальных работ [11]. Известно, что одним из важных факторов возникновения и развития внутренней патологии является хронический стресс [13].

Со времен Г. Селье влияние стресса на организм человека связывают с активацией гипоталамо-гипофизарно-адренокортикальной системы (ГГАС), конкретно с выделением гипоталамусом кортиколиберина, гипофизом - кортикотропина и надпочечниками - кортизола. Вместе с симпатико-адреналовой системой ГГАС способствует энергетической и функциональной подготовке к преодолению стресса. Эта неспецифическая реакция (общий адаптационный синдром) практически идентична для многих видов стресса [14]. Известно, что глюкокортикоиды (ГК) яВляются наиболее мощными противовоспалительными средствами. Они ингибируют на уровне транскрипции и трансрепрессии основные провоспалительные сигнальные пути: NFкB, AP-1, MAP-киназный и др. [15]. Результатом является подавление клеточного и гуморального иммунитета, в частности снижение уровня провоспалительных цитокинов: ИЛ-1 и ИЛ-6, ФНО- $\alpha$, и повышение противовоспалительных - ИЛ-4, ИЛ-10 и ИЛ-13 [18]. Такие же явления отмечаются при кратковременных курсах терапии ГК [16] и в экспериментах in vitro [18]. Имеется кажущееся противоречие между противовоспалительными механизмами стресса и его ролью в возникновении патологии, ассоциированной со стрессом и СВ [10]. Известно, что при длительной ГК-терапии способность ГК угнетать продукцию цитокинов воспаления снижается. Наблюдается резистентность рецепторов ГК [15]. Считают, что это связано с деактивацией рецепторов ГК на уровне их транскрипционной активности [19], а также со снижением активности ГГАС (синдром дезадаптации, дистресса, по Г. Селье) [20]. Во многих исследованиях различных видов стресса, таких как «производственный», «связанный с уходом за тяжело больными детьми», «низким социоэкономическим статусом», «жизненными трагедиями», “отсутствием социальной поддержки» и т.п., было выявлено не снижение, а повышение уровня цитокинов воспаления [21]. Полученные многими исследователями данные указывают на возможность как снижения уровня цитокинов воспаления под влиянием острого стрессорного эпизода, так и системного повышения провоспалительной активности при хроническом, персистирующем стрессе [10].

Повреждающее влияние гипокинезии обусловлено не только развивающимся ожирением, но и тем, что только работающие мышцы продуцируют миокины, 
модифрицирующие функции иммунной системы и противодействующие СВ [22].

Висцеральное ожирение сопровождается повышением секреции провоспалительных цитокинов: ФНО- $\alpha$, ИЛ-6 и адипокинов: лептина, резистина, а также снижением уровня противовоспалительного цитокина - адипонектина. Лица с висцеральным ожирением находятся постоянно в состоянии СВ [23].

Высококалорийная диета, богатая насыщенными жирами, с малым количеством пищевых волокон провоцирует СВ [24, 25]. Насыщенные рафинированными углеводами продукты повышают уровень СРБ независимо от массы тела и общей калорийности пищи, а также увеличивает риск развития сахарного диабета 2-го типа в 2,5 раза [26].

Нарушения обмена липидов - избыток свободных жирных кислот (ЖК) в крови и накопление метаболически активной жировой ткани в брюшной полости и других органах — являются источником СВ [27].

Липидные медиаторы осуществляют регуляцию метаболизма и воспаления через семейство из 7 трансмембранных рецепторов, ассоциированных c G-протеином (GPCR), и Толл-подобные рецепторы (ТПР), которые активируют провоспалительные ЯТФ: AP-1 и NFкB. Активируются липидами и антивоспалительные ЯТФ - рецепторы, активируемые пролиорераторами пероксисом (РАПП). Причем некоторые липиды действуют одновременно на оба типа рецепторов, осуществляя тонкую регуляцию этих процессов. Провоспалительный медиатор - лейкотриен В4 действует через свой рецептор - BLT2, также принадлежащий к семейству GPCR [27]. В макрофрагах насыщенные и ненасыщенные (n-6) ЖK активируют воспаление через ТПР2/ТПР4. В отличие от этого n-3 ненасыщенные ЖК ингибируют экспрессию ТПР2/ ТПР4 и дальнейшие пути воспаления, т.е. обладают противовоспалительным свойством [28].

Особое значение в регуляции воспаления имеют эйкозаноиды. Последние являются сигнальными молекулами, которые контролируют воспаление и иммунные процессы и оказывают влияние на развитие сердечнососудистой патологии, гипертонии, артритов и других хронических заболеваний. Они являются продуктами обмена n-6 или n-3 эссенциальных ЖK с 20 углеродными атомами, которые не синтезируются в организме человека и должны поступать с пищей. Арахидоновая кислота (АК) (n-6), n-3: докозагексаеновая (ДГК) и эйкозапентаеновая кислоты (ЭПК), источники эйкозаноидов - продуктов циклооксигеназы, липооксигеназы и эпоксигеназы: простагландинов, простациклинов, тромбоксанов и лейкотриенов. Эйкозаноиды из АК, кроме простагландина Е2 и липоксинов, оказывают преимущественно провоспалительное действие, продукты из ДГК и ЭПК - антивоспалительное действие [29]. Диета, богатая n-3 ЭПК и ДГК из рыбных продуктов, увеличивает инкорпорацию этих кислот в фрос- фролипиды мембран иммунных клеток и способствуют образованию противоспалительных продуктов этих кислот - резольвинов. Таким образом, тип ЖК определяет про- или антивоспалительный характер медиаторов, влияющих на рецепторы мембран и продукцию цитокинов. Энзиматически и неэнзиматически окисленные ЖК являются мощными индукторами воспаления. 13-(S)-гидроксиоктадекадиеноевая кислота и гидропероксид линоленовой кислоты, а также окисленные продукты AK: 15-S-гидроксиэйкозатетраеновая кислота и ее гидропероксид (15-S-ГПЕТЕ) являются медиаторами основного ядерного провоспалительного фактора: АР-1 [27]. Не только циркулирующие ЖК способствуют возникновению и поддержанию СВ. Большое значение имеют процессы в жировых депо, прежде всего в белой жировой ткани. Метаболически активная белая жировая ткань находится главным образом в брюшной полости, но при ожирении располагается также в скелетных и сердечной мышцах и других органах. Перегруженные липидами зрелье адипоциты продуцируют большое количество цитокинов воспаления: ФНО- $\alpha$, аттрактантов макрофрагов и лимфоцитов: MCP-1, CCL5, CXCL1, что приводит к инфильтрации жировой ткани макрофрагами и дальнейшей активации СВ. Это вызывает развитие ИР, сахарного диабета 2-го типа, атеросклероза, артериальной гипертонии и псориаза [30].

Связующими звеньями между СВ и внутренней патологией являются как прямое повреждающее органы и системы влияние активированных клеток и цитокинов иммунной системы, так и индуцируемая СВ инсулинорезистетность.

\section{Инсулинорезистентность}

Инсулинорезистентность - патологическое состояние, при котором взаимодействие инсулина с рецепторами в инсулинчувствительных тканях: печени, скелетных мышцах и жировой ткани не обеспечивает физиологические эффректы инсулина. Молекулярный механизм ИР заключается в частичной блокаде сигнального пути инсулина в клетке. Благодаря полной расшифровке инсулинового сигнального каскада стало известно, что цитокины СВ действуют пострецепторно, на уровне передачи сигнала от инсулинового рецептора к его субстрату (ИРС-1 и -2) и далее к фосфроинозитид-3-киназе (РIЗK), что прерывает так называемый «РІЗК-Akt» сигнальный путь, проводящий основные метаболические (анаболические) эффректы инсулина. Снижаются поглощение глюкозы гепатоцитами, адипоцитами и мышечной тканью, синтез гликогена и триглицеридов в печени, активируются гликолиз, липолиз и неогликогенез. Увеличиваются циркуляция и окисление свободных ЖК, что вызывает повреждение тканей, в том числе гепатоцитов (липотоксичность). Ключевым моментом ИР является то, что второй сигнальный путь инсулина - через митогенактивируемые протеинкиназы (МАПК), проводящий эффректы инсулина как фрактора роста, т.е. стимулиру- 
ющий пролиферацию, диффреренциацию клеток и воспаление, - не блокируется. Гипергликемия длительное время (иногда десятки лет) компенсируется повышенной продукцией инсулина - компенсаторной гиперинсулинемией. В периоде нормогликемии ИР может быть диагностирована по повышенному уровню инсулина натощак в так называемой гомеостатической модели $(\mathrm{HO}$ МА) или в тесте «эугликемический гиперинсулинемический клэмп» по пониженному клиренсу глюкозы крови после внутривенного введения инсулина [31].

Диссоциация между двумя сигнальными путями инсулина в условиях гиперинсулинемии ведет к развитию глубоких метаболических расстройств, названных G. Reaven «синдромом X» [11]. Блокада PI3K-Akt в гепатоцитах и макрофагах печени ведет к повышению продукции глюкозы и свободных ЖК, гипергликемии, гиперлипемии и развитию псориаза [32]. При истощении резервных возможностей бета-клеток островков, которые также страдают от ИР [Кумар], развивается сахарный диабет 2-го типа (CL2). Гиперинсулинемия и активация МАПК являются фракторами опухолевого роста и стимулируют развитие опухолей, в том числе опухолей кожи [33]. В эндотелии сосудов блокада PI3K-Akt пути ведет к снижению продукции оксида азота, а сохранение или увеличение активности МАР-киназного пути сохраняет или увеличивает продукцию эндотелина-1, что ведет к развитию эндотелиальной дисфункции. Это предрасполагает к возникновению артериальной гипертонии, продукции молекул адгезии макрофрагов к эндотелию и митогенной стимуляции гладкой мускулатуры сосудов, т.е. к развитию атеросклероза [32].

Общие генетические маркеры болезней системного воспаления и специфические гены псориаза

Конкретным механизмом развития кожных и суставных проявлений псориаза является экспансия макрофрагов (дендритных клеток), продуцирующих ИЛ-23, стимулирующий Th-1, Th-17 и Th-22 лимфоциты [33]. Лимфроциты секретируют большое количество провоспалительных цитокинов в кератиноцитах и синовиальных оболочках суставов: ФНО-а, ИЛ-1, ИЛ-6, ИЛ-8, ИЛ-17, ИЛ-22 и др. [33]. Это является специфическим проявлением системного воспаления в коже и связано с наличием генетической предрасположенности к псориазу [34]. Имеются общие гены, обусловливающие возникновение системного воспаления при действии внешних фракторов, и специфические гены воспаления в эндотелии сосудов при атеросклерозе и артериальной гипертонии, клетках печени при неалкогольной жировой болезни печени и других органах, что приводит к преобладанию той или иной патологии в рамках иммунометаболической болезни и обусловливает ту или иную степень коморбидности, которую, по нашему мнению, следует считать следствием синтропии внутренней патологии - фенотипической реализации СВ и ИР. Такое изменение парадигмы патогенеза псориаза привело к использованию в его терапии средств, специфически подавляющих СВ и ИР [35-38]. За минувшее десятилетие проведен ряд клинических исследований, подтверждающих позитивный эффект метформина и пиоглитазона в комплексной терапии среднетяжелых и легких форм псориаза, что одновременно решает задачу профилактики множества коморбидных состояний [39-41]. Эти средства зарекомендовали себя как эффективные и безопасные при лечении сахарного диабета 2-го типа, проявлений атеросклероза, синдрома склерозированных яичников, хронической болезни почек и других болезней, имеющих в основе СВ и ИР $[42,43]$.

\section{Заключение}

Приведенные данные позволяют считать псориаз иммуновоспалительным заболеванием, имеющим специфическую генетическую основу и общие с другими клиническими френоменами иммунометаболической болезни генетическими и внешними фракторами риска, провоцирующими СВ и ИР. Последние являются причиной тесной связи псориаза с атеросклерозом, гипертонией, сахарным диабетом 2-го типа, ожирением и другими ассоциированными заболеваниями. На момент манифестации или обострения псориаза другая патология, иногда несущая значительную угрозу для жизни и здоровья пациента, может находиться в латентном состоянии. Знание механизмов взаимосвязи накладывает на дерматологов дополнительную ответственность в плане диагностики и профилактики этих заболеваний, а также выбора средств фармакотерапии. Понимание роли СВ и ИР должно использоваться в терапии псориаза специфическими средствами, подавляющими СВ и ИР. К эффрективным и безопасным средствам такого рода, по современным данным, относятся метформин и пиоглитазон, однако применение этих препаратов при среднетяжелых и тяжелых формах псориаза, особенно у молодых людей, еще требует проведения дополнительных клинических исследований.

\section{Литература}

1. Siegel D., Devaraj S., Mitra A., Raychaudhuri S.P. Raychaudhuri S.K. and Jialal I. Inflammation, atherosclerosis, and psoriasis. Clin Rev Allergy Immunol 2013; 44: 194-204.
2. Bremmer S., Van Voorhees A.S., Hsu S., Korman N.J., Lebwohl M.G., Young M., Bebo B.F., Jr. and Blauvelt A. Obesity and psoriasis: from the Medical Board of the National Psoriasis Foundation. J Am Acad Dermatol 2010; 63: 1058—69.
3. Jensen P., Thyssen J.P., Zachariae C., Hansen P.R., Linneberg A. and Skov L. Cardiovascular risk factors in subjects with psoriasis: a cross-sectional general population study. Int J Dermatol 2013; 52 : $681-3$. 
4. Roberts K.K., A.E. Cocher, P.B. Lamb, P.J. Brown, D.F. Battafarano, E.M. Brunt, S.A. Harrison. The prevalence of NAFLD and NASH among patients with psoriasis in a tertiary care dermatology and rheumatology clinic. Alimentary Pharmacol Therap 2015; 41: 293-300.

5. Moro F., De Simone C., Morciano A., Tropea A., Sagnella F., Palla C., Scarinci E., Teti A., Caldarola G., D'Agostino M., Mancuso S., Lanzone A., Apa R. Psoriatic patients have an increased risk of polycystic ovary syndrome: results of a cross-sectional analysis. Fertil Steril 2013; 99 (3): 936—-42.

6. Gero Kramer, Dieter Mitteregger and Michael Marberger. Is Benign Prostatic Hyperplasia (BPH) an Immune Inflammatory Disease? European Urology 2007; 51: 1202-1216.

7. Tobin A.M., Veale D.J., Fitzgerald O., Rogers S., Collins P., O'Shea D. and Kirby B. Cardiovascular disease and risk factors in patients with psoriasis and psoriatic arthritis. J Rheumatol 2010; 37: 1386-94.

8. Michelle A. Lowes, Mayte Suárez-Fariñas, and James G. Krueger. Immunology of Psoriasis. Annual Review of Immunology 2014; 32: 227-255.

9. Rui Tian, Gonglin Hou Dan Li, and Ti-Fei Yuan. A Possible Change Process of Inflammatory Cytokines in the Prolonged Chronic Stress and Its UItimate Implications for Health. The Scientific World Journal. Volume 2014 (2014)

10. Rui Tian, Gonglin Hou Dan Li, and Ti-Fei Yuan. A Possible Change Process of Inflammatory Cytokines in the Prolonged Chronic Stress and Its UItimate Implications for Health. The Scientific World Journal. Volume 2014 (2014).

11. Kajdashev I.P. NF-кB-signalizaciya kak osnova razvitiya sistemnogo vospaleniya, insulinorezistentnosti, lipotoksichnosti, saharnogo diabeta 2-go tipa i ateroskleroza. Mezhdunarodnyj ehndokrinologicheskij zhurnal 2011; 3 (35); 35—40. [Кайдашев И.П. NF-кB-сигнализация как основа развития системного воспаления, инсулинорезистентности, липотоксичности, сахарного диабета 2-го типа и атеросклероза. Международный эндокринологический журнал 2011; 3 (35); 35-40.]

12. Rohleder N. Stimulation of systemic low-grade inflammation by psychosocial stress. Psychosom Med 2014; 76 (3): 181—9.

13. Miller G.E., E. Chen, J. Sze et al., "A functional genomic fingerprint of chronic stress in humans: blunted glucocorticoid and increased NF-KB signaling" Biological Psychiatry 2008; 64: 266—272.

14. Selye $H$. "The general adaptation syndrome and the diseases of adaptation" Journal of Allergy 1946; 17 : 358-398.

15. Kadmiel M. and J.A. Cidlowski, "Glucocorticoid receptor signaling in health and disease" Trends in Pharmacological Sciences 2013; 34: 518—-530.
16. Segerstrom S.C. and G.E. Miller, "Psychological stress and the human immune system: a metaanalytic study of 30 years of inquiry," Psychological Bulletin, vol. 130, no. 4, pp. 601-630, 2004

17. Miller G.E., Cohen S. and Ritchey A.K., "Chronic psychological stress and the regulation of pro-inflammatory cytokines: a glucocorticoidresistance model," Health Psychology 2002; 21: $531-541$.

18. Busillo J.M., K. M. Azzams, and J. A. Cidlowski, "Glucocorticoids sensitize the innate immune system through regulation of the NLRP3 inflammasome," The Journal of Biological Chemistry 2011; 286: 38703-38713.

19. Ramamoorthy S. and J.A. Cidlowski, "Exploring the molecular mechanisms of glucocorticoid receptor action from sensitivity to resistance," Endocrine Development, vol. 24, no. 41, p. 56, 2013.

20. Selye $\mathrm{H}$. "Confusion and controversy in the stress field". Journal of Human Stress 1975; 1 (2): 37-44.

21. Calcagni E. and I. Elenkov, "Stress system activity, innate and Thelper cytokines, and susceptibility to immune-related diseases," Annals of the New York Academy of Sciences 2006; 1069: 62-76.

22. Bruunsgaard H. Physical activity and modulation of systemic low-level inflammation. Journal of leukocyte biology 2005; 78: 819-3.

23. Bastard J-P., Maachi M., Lagathu C., Kim M.J., Caron M., Vidal H. et al. Recent advances in the relationship between obesity, inflammation, and insulin resistance. European cytokine network 2006; 17: 4-12

24. Calder P.C., Kew S. The immune system: a target for functional foods? Brit J Nutr 2002; 88 Suppl 2: S165-77.

25. Trayhurn P., Wood I.S. Adipokines: inflammation and the pleiotropic role of white adipose tissue. Brit J Nutr 2004: 92: 347-55.

26. Salmeron J., Manson J.E., Stampfer M.J., Colditz G.A., Wing A.L., Willett W.C. Dietary fiber, glycemic load, and risk of non-insulin-dependent diabetes mellitus in women. JAMA 1997; 277: 472-7.

27. Wahli W., L. Michalik. РАППs at the crossroads of lipid signaling and inflammation. Trends in Endocrinology \& Metabolism 2012; 23 (7): 351-363.

28. Dasu, M.R. et al. Toll-like receptors and diabetes: a therapeutic perspective. Clin Sci 2012; 122: 203-214

29. Shimizu T. Lipid mediators in health and disease: enzymes and receptors as therapeutic targets for the regulation of immunity and inflammation. Annu Rev Pharmacol Toxicol 2009; 49: 123-150.

30. Dowlatshahi E.A., van der Voort E.A., Arends L.R., Nijsten T. Markers of systemic inflammation in psoriasis: a systematic review and meta-analysis. Br J Dermatol 2013 Aug; 169 (2): 266—82.
31. DeFronzo R., Tobin J., Andres R. Glucose clamp technique: a method for quantifying insulin secretion and resistance. Am J Physiol 1979; 237: 214-223.

32. Boehncke S., Thaci D., Beschmann H. Ludwig R.J., Ackermann H., Badenhoop K. and Boehncke W.H. Psoriasis patients show signs of insulin resistance. $\mathrm{Br}$ J Dermatol. 2007; 157: 1249—51.

33. Nograles K.E., Zaba L.C., Shemer A. et al. (2009) IL-22-producing "T22" T cells account for upregulated IL-22 in atopic dermatitis despite reduced IL17-producing TH17 T cells. J Allergy Clin Immunol 123: $1244-1252$.

34. Vinod Chandran. Genetics of psoriasis and psoriatic arthritis. Indian J dermat 2010; 55920: 151-156.

35. Kolehmainen M., S. M. Ulven, J. Paananen, V. et al. Healthy Nordic diet downregulates the expression of genes involved in inflammation in subcutaneous adipose tissue in individuals with features of the metabolic syndrome. Am J Clin Nutr, 2014; 101 (1): 228.

36. Won-Ha Leea,b,d, Tae-Hong Hwangb, Goo Taeg Ohc, Sung Uk Kwona, Yoon-Ho Choia and Jeong. Genetic factors associated with endothelial dysfunction affect the early onset of coronary artery disease in Korean males. Vascular Medicine 2001; 6: 103-108.

37. Dongiovanni P, Anstee Q.M, and L. Valenti. Genetic Predisposition in NAFLD and NASH: Impact on Severity of Liver Disease and Response to Treatment. CurrPharmDes 2013; 19(29): 5219—523.

38. Glossmann H., Reider N. A marriage of two "Methusalem" drugs for the treatment of psoriasis? Arguments for a pilot trial with metformin as add-on for methotrexate. Dermatoendocrinol 2013; 5 (2): 252-63.

39. Shafiq N., Malhotra S., Pandhi P., Gupta M., Kumar B., Sandhu K. Pilot trial: Pioglitazone versus placebo in patients with plaque psoriasis (the P6). Int J Dermatol 2005 Apr; 44 (4): 328—33.

40. Deborah Brauser. Pioglitazone Combined With Acitretin Appears Safe, Effective for Moderate to Severe Chronic Plaque-Type Psoriasis. Arch Dermatol 2009; 145: 387-393.

41. Hamminga E.A., van derLely A.J., Neumann H.A., Thio H.B. Chronic inflammation in psoriasis and obesity, implications for therapy. Med Hypotheses 2006; 67: 768-73.

42. Benoit Viollet, Bruno Guigas, Nieves Sanz Garcia et al. Cellular and molecular mechanisms of metformin: an overview. Clin Sci (Lond) $2012 \mathrm{Mar}$; 122(6): 253-70

43. Schernthaner G., Craig J. Currie, Gerit-Holger Schernthaner. Do we still need pioglitazone for the treatment of type 2 diabetes? A risk-benefit critique in 2013. Diabetes Care; 36 Suppl 2:S155—61.

об авторе:

М.С. Расин - Д.м.н., профессор кафедры внутренней медицины № 3 ВГУЗ «Украинская медицинская стоматологическая академия», Полтава

\section{Конфликт интересов}

Автор заявляет об отсутствии потенциального конфрликта интересов, требующего раскрытия в данной статье 